\title{
BIOPOLÍTICA, SAÚDE E GOVERNAMENTALIDADE: A INDÚSTRIA FARMACÊUTICA NA SOCIEDADE GLOBALIZADA
}

\author{
Aritana da Silveira Machado ${ }^{1}$ \\ Juarez Fernandes Junior ${ }^{2}$
}

\begin{abstract}
RESUMO
Partido das concepções sobre biopolítica traçadas por Michel Foucault, o presente artigo tem como escopo abordar a indústria farmacêutica na sociedade globalizada e consumista como instrumento de manutenção do projeto biopolítico de controle social. Para isso, buscou-se compreender a governamentalidade e o aparato biopolítico da indústria de fármacos a fim de identificar os desafios à regulação jurídica que assegure o direito à saúde. A pesquisa desenvolveu-se com base na Teoria Sistêmica que viabiliza um enfoque complexo e interdisciplinar sobre o tema. O método de abordagem utilizado foi $o$ dedutivo e o método de procedimento foi o histórico e comparativo. Quanto à técnica de pesquisa, utilizou-se a documental e bibliográfica.
\end{abstract}

Palavras-chave: Biopolítica; Governamentalidade; Michael Foucault; Indústria farmacêutica.

\section{BIOPOLYTICS, HEALTH AND GOVERNMENTALITY: THE PHARMACEUTICAL INDUSTRY IN THE GLOBALIZED SOCIETY}

\begin{abstract}
Regarding the conceptions on biopolitics outlined by Michel Foucault, this article aims to approach the pharmaceutical industry in the globalized and consumerist society as an instrument of maintenance of the biopolitical project of social control. In order to do this, we sought to understand the governmentality and biopolitical apparatus of the drug industry in order to comprehend the challenges to the legal regulation that guarantees the right to health. The research was developed based on the Systemic Theory that allows a

\footnotetext{
${ }^{1}$ Advogada. Pós-graduada em Direito Constitucional; Mestranda em Direito pelo PPDG da Universidade Federal de Santa Maria (UFSM); Pesquisadora do Grupo de Pesquisa "Propriedade Intelectual na Sociedade Contemporânea; aritanasm@ hotmail.com.

${ }^{2}$ Advogado. Bacharel em Direito pela Faculdade de Direito de Santa Maria (FADISMA). Facilitador Judicial no Juizado da Paz Doméstica da Comarca de Santa Maria. Mediador e Facilitador do Centro de Mediação e Práticas Restaurativas (CEMPRE). Membro do Grupo de Pesquisa em Propriedade Intelectual na Contemporaneidade (GPPIC). Mestrando em Direito pela Universidade Federal de Santa Maria (UFSM). Pós Graduando em Justiça Restaurativa e Mediação de Conflitos no Âmbito Público e Privado (FADISMA). Estudante do Programa de Formação de Professores para Educação Profissional Superior (UFSM). Endereço eletrônico: juarez@fernandesjr.com.
} 
complex and interdisciplinary approach on the subject. The deductive method was used, while the procedure method was the historical and comparative one. As for the research technique, the documentary and bibliographical one was used.

Keywords: Biopolitics; Governmentality; Michel Foucault; Pharmaceutical industry.

\section{CONSIDERAÇÕES INICIAIS}

Nas sociedades modernas a preocupação em viver uma vida saudável é tão latente que os comportamentos de prevenção e o culto à saúde são utilizados midiaticamente para estabelecer um padrão ideal de vida saudável. Para isso, a lógica de consumo é empregada tanto para aliviar o sentimento de dor como também para atingir o padrão de corpo saudável, a fim de que o indivíduo se sinta inserido socialmente. A forma de exercer o poder sobre as pessoas, na medida em que o Estado parceiro da mídia e do interesse econômico de determinado atoresregulamenta a vida, é denominado por Michel Foucault como biopolítica.

A noção de biopolítica foi construída por ele no decorrer dos seus cursos ministrados nos anos de 1970, como sendo a arte de governar, ou seja, a ideia de uma governamentalidade à serviço da regulamentação ou estratégia de segurança a qual tem a vida como objeto de investimento. Para Foucault, a biopolítica quando aplicada à população, atua a partir da regulação das multidões, valendo-se de instrumentos que permitam controlar e gerir aspectos diretamente ligados à vida dos indivíduos.

Nesse sentido, busca-se com o presente artigo investigar em que medida a indústria farmacêutica na sociedade globalizada está a serviço da manutenção do projeto biopolítico de controle social. Para isso, no primeiro capítulo analisar-se-á o cenário da indústria farmacêutica no sociedade globalizada a partir do Acordo sobre aspectos dos Direitos de Propriedade Intelectual Relacionados ao Comércio (Acordo TRIPS) que, ao garantir o direito de exclusividade ao inventor, causou consideráveis implicações no campo da saúde.

No segundo capítulo abordar-se-á o aparo bipolítico daindústria farmacêutica a partir do conceito foucaultiano de biopoder e governamentalidade, a fim compreender as técnicas de dominação em massa a partir do viés da saúde. Por fim, o terceiro capítulo se ocupa em analisar os desafios à regulação jurídica do direito à saúde diante do cenário atual onde o setor farmacêutico está à serviço da lógica de consumo.

Rev. de Direito, Globalização e Responsabilidade nas Relações de Consumo | e-ISSN: 2526-0030| Goiânia| v. 5 
Destarte, a presente pesquisa como Teoria de Base a Teoria Sistêmica, a qual representa-se através de um pensamento contextualizado. Quanto ao método de abordagem o mesmo é indutivo, o método de procedimento utilizado foi histórico e comparativo, e a técnica de pequisa foi a documental e bibliográfica.

\section{A INDÚSTRIA DE MEDICAMENTOS NA SOCIEDADE GLOBALIZADA}

O domínio tecnológico das grandes empresas transnacionais e o poder político e econômico que transita sem fronteiras em busca de lucros foi arquitetado a partir de interesses econômicos de atores internacionais que reproduzem a lógica da colonialidade. Isso resulta da ampliação dos padrões internacionais de regulação dos direitos de propriedade intelectual previsto originalmente na Convenção da União de Paris (CUP).

O cenário de negociação do Acordo TRIPS, instrumento máximo de proteção às patentes foi marcado pelo forte interesse econômico dos países do Norte, uma vez que, possuidores da tecnologia, estabeleceram "unilateralmente" no âmbito da Organização Mundial do Comércio (OMC) regras mínimas a serem seguidas pelos Estados membros. A partir daí, beneficiou as indústrias farmacêuticas, diante de um monopólio, passaram a ditar as regras de mercado e estabelecer quais medicamentos seriam desenvolvidos e comercializados.

Nesse sentido, segundo Maristela Basso (2005, p. 26) os estadunidenses foram "os principais arquitetos do processo global de re-regulamentação dos direitos de propriedade intelectual" juntamente com setor farmacêutico, gerando a uniformização das legislações nacionais de Propriedade Intelectual com a entrada em vigor do Acordo TRIPS, que desconsiderou os variáveis níveis de desenvolvimento tecnológico dos países membros da OMC, ocasionando grandes problemas para os para os países do Sul Social. ${ }^{3}$

\footnotetext{
${ }^{3} \mathrm{O}$ Sul é aqui concebido como um campo de desafios sistêmicos, que procuram reparar os danos e impactos historicamente causados pelo capitalismo na sua relação colonial com o mundo. Esta concepção do Sul sobrepõe- se em parte com o Sul geográfico, o conjunto de países e regiões do mundo que foram submetidos ao colonialismo europeu e que, com exceções como, por exemplo, da Austrália e da Nova Zelândia, não atingiram níveis de desenvolvimento econômico semelhantes ao Norte global (Europa e América do Norte). A sobreposição não é total porque, por um lado, no interior do Norte geográfico classes e grupos sociais muito vastos (trabalhadores, mulheres, indígenas, afrodescendentes, muçulmanos) foram sujeitos à dominação capitalista e colonial, e por outro lado, porque no interior do Sul geográfico houve sempre as 'pequenas Europas', pequenas elites locais que beneficiaram da dominação capitalista e colonial e que depois das independências a exerceram e continuam exercer, por suas próprias mãos, contra classes e grupos
} 
Hodiernamente, as indústrias farmacêutica sem grandes obstáculos se articulam dentro dos países do sul global a partir da criação de instrumentos técnicos rigorosos ancorados em princípios como do livre comércio, da privatização, da desregulação e da reforma das normas estatais internas. Além disso, impõem diretrizes aos governos que desejam ou precisam dos seus benefícios e, ainda, pressionam o Estado para garantir condições de manutenção e ampliação do capital, da produção e do consumo (SANTIN, p. 3028).

Ao produzir medicamentos de elevados custos comerciais, as grandes corporações deixaram de investir em pesquisa e desenvolvimento para determinados grupos de doenças em razão do baixo valor de mercado. Diante da falta de interesses das industrias de fármacos em produzir esses medicamentos e do direito de explorar economicamente um produto pelo prazo de vinte anos, grande parte da população não tem acesso a medicamentos essenciais, seja pelo desinteresse em continuar produzindo aquela droga ou pelo falta de investimento em pesquisa, ambas as hipóteses decorrentes do baixo retorno financeiro (SANTIN, p. 3048).

Essa realidade tende a ser mais preocupante nos países do sul social, pois as barreiras postas faz como que o sistema patentário reforce os direitos do titular da patente, o que, consequentemente, restringe o acesso aos medicamentos, visto que o retorno financeiro que o medicamento pode render à indústria que o desenvolveu, faz com que seja realizada a produção de determinados fármacos que são mais lucrativos em detrimento de outros menos lucrativos.

De acordo com Sparemberger e Zanoelo (2010, p. 396):

As recentes evoluções mostram claramente que o sistema de patentes se transformou em instrumento essencial para as empresas transnacionais no âmbito da concorrência internacional, tornando as mesmas o centro de interesse dos regimes de propriedade intelectual. A maioria das modificações efetuadas nos últimos anos no direito de patentes deu-se no sentido de reforçar sistematicamente os direitos do titular da patente, reduzindo as obrigações e os deveres que lhe eram impostos.

Cumpre asseverar que setores da biotecnologia, instigados pelo capitalismo moderno, vêem na biodiversidade dos países do Sul uma vasta e próspera fonte mercadológica, já que possuem a matéria-prima para desenvolver produtos e alimentarem

subordinados. Boaventura de Sousa Santos e Maria Paula Meneses (2010, p. 19).

Rev. de Direito, Globalização e Responsabilidade nas Relações de Consumo | e-ISSN: 2526-0030| Goiânia| v. 5 
o mercado internacional. Nesse liame, os conhecimentos tradicionais tornam-se passíveis de espoliação, na medida em que passam para esfera individual e monopolista das grande corporações internaionais do Norte, e para tornam-se produtos de altíssimos preços e inacessíveis a grande parte da população.

Atualmente a indústria de fármaco é um dos setores que mais cresce anualmente. Em 2014 o mercado farmacêutico faturou cerca US\$ 1 trilhão sendo responsável por 70\% da demanda os países de origem das maiores empresas farmacêuticas do mundo, as chamadas "big fharmas". Formada por Estados Unidos, Europa Ocidental e Japão, geralmente são empresas envolvidas em todas as fases necessárias para a venda de medicamento, que inicia com a pesquisa e desenvolvimento (P\&D), passando pela regulação, manufatura e marketing, até chegar na comercialização do remédio (PIMENTAL, et. al., 2014).

Até a metade do século XX, empresas alemãs e suíças lideravam o mercado farmacêutico que até então era uma divisão da indústria química, sendo as indústrias estadunidenses apenas empresas de pequeno porte atentas à comercialização. Segundo Mckelvey e Orsenigo (2001) empresas alemãs eram responsáveis por $80 \%$ da produção mundial de fármacos.

Não obstante, o Estado norte-americano se consolidou no mercado farmacêutico a partir da II Guerra Mundial, após a revolução de penicilina, como resultado da intervenção do governo para promover o investimento do setor privado em Pesquisa e Desenvolvimento (P\&D) de medicamentos aliado ao papel das universidades no estabelecimento e na difusão das pesquisas feitas pelos laboratórios privados (RADAELLI, 2012).

De acordo com Radaelli (2008), o desenvolvimento da penicilina e suas consequências comercias e tecnológicas foram decisivas para a ascensão da indústria farmacêutica dos Estados Unidos. Isso, porque possibilitou ao país experiências nas pesquisas à base de antibióticos, produto que anos mais tarde teria papel central no mercado mundial.

Por derradeiro, após o Acordo TRIPS, as multinacionais farmacêutica migraram substancialmente para o sul global. Com grande investimento em P\&D nesses países, com destaque ao Brasil diante da sua rica biodiversidade, o faturamento anual é elevadíssimo. 
De acordo com o Anuário Estatístico do Mercado Financeiro de 2016 publicado pela Agência Nacional de Vigilância Sanitária (Anvisa) em 2017, no Brasil, o mercado farmacêutico faturou acerca de R \$ 63,5 bilhões no ano de 2016 com a venda de 4,5 milhões de embalagens (ANVISA, 2016).

No mesmo ano, 214 empresas comercializaram 12.798 apresentações catalogadas pela Anvisa como produtos novos, biológicos, genéricos, similares e específicos. Os medicamentos classificados como novos lideraram o ranking do faturamento desse setor, somando mais de 25 milhões decorrentes da comercialização de mais de 925 milhões de embalagens (ANVISA, 2016).

Destarte, torna-se evidente que os medicamentos se tornaram bens de consumo na sociedade globalizada, na medida em que o setor de fármacos se articula a partir da criação de novos remédios a cada ano. É comum encontrar farmácias e drogarias a cada esquina oferecendo uma pluralidades de remédios para os mais variados sintomas, configurando a tríade clássica da relação consumista: fornecedor, consumidor e produto. Além dos índices de dependência causado pelos medicamentos, a automedicação é um dos fatores decorrentes do elevado consumo de medicamentos pela população.

Diante disso, cumpre enfrentar o problema da medicalização na sociedade globalizada não somente a partir da relação entre o paciente (consumidor) e os serviços de saúde (fornecedor), mas também dos inúmeros fatores externos. Segundo a antropóloga Mary Douglas e Baron Isherwood (2004), as relações sociais são determinantes na escolha dos hábitos e dos padrões a serem seguidos pelos indivíduos.

Logo, o consumo pode ser um instrumento de exclusão, servindo como "marcador social que origina grupos hierárquicos na sociedade, os bens tangíveis e intangíveis posicionam pessoas em relação a uma determinante fundamental de poder em torno da qual gravitam diferentes posições sociais" (PANJOTA, 2018).

Diante de uma sociedade industrial pautada no modelo capitalista, a lógica de consumo perpassa por todas questões que envolvem a vida humana, o que inclui a saúde. A constante busca em amenizar a dor e o sofrimento está a serviço do mote midiático que estabelece a lógica consumista em relação aos medicamentos. Por isso, torna-se importante abordar as questões que envolvem saúde, em especial a noção de biopolítica, que proporciona uma visão crítica sobre as políticas de saúde, os instrumentos normativos 
e a participação das populações, a partir das ideias foucaultianas sobre bipolitica, segurança e população.

\title{
2 A GOVERNAMENTALIDADE E O APARATO BIOLÍTICO DA INDÚSTRIA FARMACÊUTICA
}

\begin{abstract}
“O que é governar um navio? É certamente se ocupar dos marinheiros, da nau e da carga; governar um navio é também prestar atenção aos ventos, aos recifes, às tempestades, às intempéries, etc.; são estes relacionamentos que caracterizam o governo de um navio. Governar uma casa, uma família, não é essencialmente ter por fim salvar as propriedades da família; ter como objetivo os indivíduos que compõem a família, suas riquezas e prosperidades; é prestar atenção aos acontecimentos possíveis, às mortes, aos nascimentos, às alianças com outras famílias; é esta gestão geral que caracteriza o governo [...] O essencial é portanto este conjunto de coisas e homens; o território e a propriedade são apenas variáveis.”
\end{abstract}

Michel Foucault-Microfísica do Poder

A biopolítica nasce como forma de poder sobre os fenômeno da vida, do nascimento, da saúde e da morte, "são fenômenos coletivos, que só aparecem com seus efeitos econômicos e políticos, que só se tornam pertinentes no nível da massa" (FOUCAULT, 2000, p. 293). Para Foucault, o poder se articula no discurso, no saber, tornando-se um mecanismo político de regulação da vida da população, motivo pelo qual deve ser compreendido não como regra e proibição e, sim, como microfísica, uma força positiva que se configura a partir da junção dos saberes e práticas que possuem uma profundidade tanto estética como ética, implicadas com a construção de modos de existência (NESPOLI, 2014, p.62).

Para Foucault (2209), uma das forma de exercer o poder inicialmente é através do encarceramento dos corpos nas fábricas, conventos, prisões, escolas, hospitais e exércitos. Como mecanismo disciplinar tem-se o panóptico ${ }^{4}$, originalmente desenvolvido pelo filósofo Jeremy Benthan em 1971, em que as instituições modernas ordenadas pelo modelo arquitetônico "o olho que tudo vê", são dispositivos desenvolvidos a partir de tecnologias de poder que examinam, classificam, punem, normalizam e regulam os corpos.

De acordo com compreensões de Nespoli (2014, p. 65), Foucault identifica a

\footnotetext{
${ }^{4}$ Neste projeto haveria uma torre central que poderia ver os presos em cada uma de suas celas, porém os presos não veriam quem poderia estar vigiando-os.
} 
biopolítica como outra forma de exercer o poder sobre as pessoas, na medida em que ela regulamenta a vida a partir do poder contínuo e científico de se "fazer viver ou deixar morrer”. Dessa forma, a biopolítica atua como um dispositivo de governo, relacionado à maneira correta de dispor as coisas e conduzi-las a um bem comum, onde as leis servem como táticas de governo.

Decorrem dos novos arranjos populacionais a necessidade do controle de dados e estatísticas sobre doenças como mecanismos de prevenção. Corroborando com a tese foucaultiana, o ser humano ocidental passa, então, a experimentar um novo modelo de vida, em que a questão biológica tem reflexo na esfera política. Esse novo modelo condiciona a vida em coletividade, cujos fatores como longevidade, reprodução, natalidade, mortalidade, migração, dentre outros, proporcionam uma visão mais ampla para o Estado sobre as condições da sua população (BOTH, 2008).

Segundo Caponi (2009), a indústria farmacêutica desempenha papel crucial nesse processo, pois investindo em pesquisa e desenvolvimento de novos medicamentos corrobora com as estratégias biopolíticas de controle populacional por parte do estado. Essa estratégia de poder e controle tem como escopo encaixar os indivíduos enquanto coletividade a um padrão de normalidade com a promessa da imediata solução do sofrimento. Assim, reduz-se ao campo biológico qualquer aspecto da condição humana, conduzindo a uma máxima de normal ou anormal.

\begin{abstract}
A saúde deixou de ser a "vida no silêncio dos órgãos", usando a expressão feliz de Leriche. Ela exige autoconsciência de ser saudável, deve ser exibida, afirmada continuamente e de forma ostentosa, constituindo um princípio fundamental de identidade subjetiva. A Saúde perfeita tornou-se a nova utopia apolítica de nossas sociedades. Ela é tanto meio quanto finalidade de nossas ações. Saúde para a vida. Mas também viver para estar em boa saúde. Viver para fazer viver as biotecnologias (ORTEGA, 2004, p. 14).
\end{abstract}

Nessa pespectiva, asseveram Machado e Lessa (2012), que a lógica consumista fomentada pelas corporações farmacêuticas faz parecer que a busca por uma normalidade, definida em determinados padrões é impossível de ser atingida. Assim, as indústrias farmacêuticas operam a partir da ideia de que felicidade ou a anormalidade são alçadas somente com o uso de medicamentos.

Muito além do simples e indefinível efeito farmacológico objetivo, todo remédio também é uma representação que se auto-reforça por meio do efeitoplacebo inerente a todo medicamento. O que se vende com o mercado de drogas são modos de produção da subjetividade. Assim o fazem os usuários que as inserem em contextos sociais, cerimoniais e até rituais. Também assim 
o consideram as agências publicitárias que, ao promoverem álcool, tabaco ou remédios, vendem estados de espírito, modelos de felicidade da alma, humor em pílulas. Mais do que venderem, exacerbam, pois, conforme a hipnótica cantilena publicitária, só há requinte com um cigarro na mão, só há festa com cerveja e decotes generosos, só há felicidade plena com o sono, a ansiedade e a tristeza geridos por meio de doses de pílulas ou elixires. (CARNEIRO, 2011, $\mathrm{s} / \mathrm{p})$.

Na conjuntura biopolítica, de acordo com Tybusch e Tybusch (2013) a tecnologia do poder, antes articulada na disciplina do indivíduo e do seu corpo, dá espaço para a gestão da vida sobre a coletividade, ou seja, o controle não é mais sobre o corpo enquanto espécie, mas sim enquanto multidão. Segundo os autores, "o objetivo é abordar o controle direto sobre essa população para os mais diferentes motivos como estratégias de segurança do Estado, incentivo ao consumo e a racionalidade econômica, bem como suporte de processos biológicos (nascimentos, mortalidade, epidemias e longevidade)". Trata-se de "levar em conta a vida, os processos biológicos do homem-espécie e de assegurar sobre eles não uma disciplina, mas uma regulamentação" (FOUCAULT, 2000, p. 294). Desse modo, a biopolítica atua como um mecanismo de governo, ou seja, como uma governamentalidade, onde as lei servem de táticas de controle do Estado.

Por esta palavra, "governamentalidade", entendo o conjunto constituído pelas instituições, os procedimentos, análises e reflexões, os cálculos e as táticas que permitem exercer essa forma bem específica, embora muito complexa, de poder que tem por alvo principal a população, por principal forma de saber a economia política e por instrumento técnico essencial os dispositivos de segurança. Em segundo lugar, por "governamentalidade" entendo a tendência, a linha de força que, em todo o Ocidente, não parou de conduzir, e desde há muito, para a preeminência desse tipo de poder que podemos chamar de "governo" sobre todos os outros - soberania, disciplina - e que trouxe, por um lado, o desenvolvimento de toda uma série de aparelhos específicos de governo [e, por outro lado], o desenvolvimento de toda uma série de saberes. Enfim, por "governamentalidade", creio que se deveria entender o processo, ou antes, o resultado do processo pelo qual o Estado de justiça da Idade Média, que nos séculos XV e XVI se tornou o Estado administrativo, viu-se pouco a pouco “govermentalizado" (FOUCAULT, 2008b, p. 143-144).

Portanto, a biopolítica se fortalece a partir dessa governamentalidade, que delimita a função do Estado, na medida em que integra normas jurídicas e, principalmente, cria dispositivos de segurança. Nesse sentido, a sociedade civil ${ }^{5}$, segundo Foucault possibilita

\footnotetext{
${ }^{5}$ De acordo com Foucault (2008, p. 404): “A sociedade civil não é uma realidade primeira e imediata. A sociedade civil é uma coisa que faz parte da tecnologia governamental moderna. Dizer que ela faz parte dessa tecnologia não quer dizer que seja o seu produto puro e simples, mas também não quer dizer que não tem realidade".
} 
ao lado da ideia de homo oeconomicus, o governo da vida (NESPOLI, 2014, p. 73).

\begin{abstract}
Considerando a afirmação de que o Homo Oeconomicus e a Sociedade Civil pertencem ao mesmo conjunto para a formação da "tecnologia da governamentalidade liberal", percebe-se que estas duas construções, juntamente com a ideia própria de governamentalidade, são necessárias para a confirmação da tecnologia do biopoder, da biopolítica. É necessário salientar, que a sociedade civil como um conceito de tecnologia governamental deve, juntamente com o governo, inserir-se juridicamente à uma economia entendida como processo de produção e de troca. Na realidade, a sociedade civil é definida por Michel Foucault como realidade transacional, uma estrutura que trabalha com relações de poder na interface entre governantes e governados (TYBUSCH e TYBUSCH, 2013).
\end{abstract}

Retomando a ideia do panóptico citada anteriormente, percebe-se que diante da estrutura da biopolítica que tem como fito controlar multidões, o modelo "poucos que observam muitos" desenvolvido por Bentham dá lugar ao sinóptico. A estratégia biopolítica de controle populacional se dará a partir da lógica que "muitos observam e vinculam a poucos”. Assim, o Estado-Corporação aliado do Homo Oeconomicus, determina as escolhas da coletividade sobre questões como saúde e consumo (TYBUSCH e TYBUSCH, 2013).

Asism, percebe-se que a saúde é utilizada como estratégia de poder que delimitam o sujeito, encaixando-o em uma ideia de normalidade pré-estabelecida. A lógica de consumo da sociedade moderna fomenta no indivíduo a constante necessidade de pertencimento que por trás alimenta interesses econômicos de certo atores estatais e globais.

Nesse diapasão, grandes multinacionais do setor farmacêutico utilizam estratégicas biopolíticas para divulgarem novas doenças e remédios diante de uma sociedade civil consumista, tornando-se um desafio ao Estado-Corporação uma regulação jurídica que promova o direito à saúde.

\title{
3 DESAFIOS À REGULAÇÃO JURÍDICA: A VERDADE E AS FORMAS JURÍDICAS PARA COMPREENSÃO DA NECESSIDADE DE GARANTIR O DIREITO À SAÚDE
}

Atualmente, muitos dos discursos sobre a saúde e a sua promoção se ocupam de discursos sobre erradicação de doenças. Para isso, estabelecem zonas de normalidades e 
comportamentos sadios em oposição às áreas que não atingem esse patamar. Com isso, há o rompimento da fronteira entre saúde e doença, que "em nome da erradicação absoluta dos riscos, o ambiente social é esquadrinhado pelo discurso da promoção da saúde em suas dimensões físicas, psíquicas e sociais, alargando crescentemente o espaço de monitoramento e controle das ações (FURTADO; SZAPIRO, 2012, p.820).

No livro A verdade e as formas jurídicas, Foucault (1999, p.8) busca demonstrar de que forma as práticas sociais podem arquitetar domínios de saber que não apenas aparentam ser novo objetos, novos conceitos, novas técnicas, como também criam novas formas totalmente novas de sujeitos e de sujeitos de conhecimento, ou seja, como a práxis cria saberes e este cria sujeitos, conceitos e objetos.

A nova forma de governança global faz com que as indústrias farmacêuticas do norte dominem os países do sul (periféricos) na medida em que reafirmam as assimetrias econômicas e políticas do sistema internacional. As regras de proteção à propriedade intelectual no âmbito internacional cada vez mais tornam-se favoráveis aos interesses das grandes empresas transnacionais e dos países desenvolvidos do sistema capitalista. Ao invés de fomentar o crescimento tecnológico em países em desenvolvimento, o Acordo TRIPS fortaleceu o aumentando da lacuna econômica.

O sistema internacional de proteção à propriedade intelectual foi criado com o objetivo de estabelecer internacionalmente parâmetros que equalizassem as legislações internas dos estados sobre a proteção do intelecto no tange a criações industriais, científicos, artísticos e literários. No campo no domínio industrial, a proteção se dá através do instituto da patente que garante ao inventor o direito de explorar economicamente o seu produto.

Ocorre que com o advento do Acordo sobre aspectos dos Direitos de Propriedade Intelectual Relacionados ao Comércio (Acordo TRIPS), a concessão da exclusividade de exploração pelo inventor impactou diretamente o campo da saúde, especificamente o direito de acesso a medicamento.

Nesse sentido,

A biopolítica intervém no "como" da vida, isto é, na maneira como as pessoas devem viver, cuidar de si, para assim buscarem aumentar sua expectativa de vida e controlar seus riscos. E, se o elemento que se encontra na interface entre o disciplinar e o regulamentador é a "norma", esta constitui uma síntese capaz de ser aplicada simultaneamente ao corpo individual e à diversidade 
populacional, possibilitando um controle único que captura a ordem disciplinar do corpo e os acontecimentos de uma multiplicidade populacional. A normalização, portanto, constitui-se como um modo de reprodução do biopoder que, de resto, transforma uma política pública de saúde numa questão de controle das iniciativas pessoais (FURTADO; SZAPIRO, 2012, p. 819).

A participação dos estados na elaboração de uma lei é fundamental para manutenção da governabilidade, pois além de gerar cumplicidade, por vezes, implica também em obediência. Diante disso, questiona-se: "como então promover uma participação políticacapaz de gerar novas formas de "governo da vida" no interior da máquina governamental? Como construir outras vias, outras racionalidades governamentais, capazes de gerir políticas de participação que tenham a defesa da vida como principal critério e objetivo? Como encher a vida de novos sentidos?" (NESPOLI, 2014, p. 87).

Segundo Grasiele Nespoli, são perguntas simples mas que exigem respostas complexas. Para tanto, a autora propõe como alternativa o biopoder reverso, transformado em biopotência, em potência de vida, em luta constante pela defesa da saúde como direito. Para colocar o poder em favor da vida, segundo ela:

\footnotetext{
São necessários, minimamente, desejo e criação. O desejo é "a potência da capacidade ativa de existir" (Fuganti, 2009, p. 672), e a criação é o que torna possível romper aquilo que se conserva, portanto exige abandono e autonomia. Porém, o desejo, quando investido pelo capital, serve como limite, como força de conservação do estado de vida, dos modos de pensar e agir no mundo, das verdades, mas quando investido de vontade de criação pode ser o motor de uma ação política emancipatória. Não há participação sem capacidade ativa de existir e sem abertura para o novo (NESPOLI, 2014, p. 88).
}

Ocorre que o controle biopolítico arranjado nas estruturas societárias atualmente são uma nova roupagem do que antes era gestão de controle por parte do Estado na vida biológica dos corpos e das populações. Por derradeiro, hoje pode ser compreendido como o agenciamento simbólico das técnicas e serviços da saúde por parte da empresa biotecnológica.

Segundo Junges (2009, p. 290), ambos instrumentos de controle estão presente, o primeiro a partir da perspectiva biológica, ao passo que o segundo, de caráter consumista e simbólico. Isso, porque segundo Foucault (1979), a organização do biopoder foi necessária para o capitalismo se desenvolver, na medida em que os corpos disciplinados dos trabalhadores eram inseridos na lógica da produção.

A proteção de exploração conferida ao titular da patente está diretamente atrelada aos 
interesses dos países desenvolvidos titulares dos conhecimentos tecnológicos, tornando os países do sul reféns de um sistema global de propriedade intelectual que assegura a manutenção da posição de poder do norte social.

De acordo com Chang (2004), no período em que a CUP orientava os sistemas nacionais de propriedade intelectual, havia a possibilidade dos estados modificarem suas legislações internas a fim de promover o desenvolvimento de setores tecnológicos. Assim, quando determinado Estado apresentava um nível tecnológico competitivo no mercado internacional, as patentes eram reconhecidas.

Importante destacar que foi inserida na agenda de discussões da IV Conferência Ministerial da OMC ocorrida em Doha no ano de 2001, Qatar, o tema da Propriedade Intelectual e o acesso a medicamentos. Nesse evento, foi aprovada a Declaração de Doha, considerada importante instrumento político na medida em que possibilitou aos países em desenvolvimento articular as flexibilidades previstas no Acordo TRIPS em relação à saúde. Segundo Polonio (2006, p. 169):

\begin{abstract}
A "Declaração sobre o Acordo TRIPS e a Saúde Pública" é um Documento fundamental de interpretação dos limites da proteção dos direitos de propriedade intelectual, especialmente em relação às patentes farmacêuticas e à adoção de políticas públicas na área da saúde. Nesse sentido, por meio de deliberação aprovada durante a $4 \S$ Conferência Ministerial da OMC, realizada em Doha, e em consonância com diversas Convenções sobre direitos humanos, reconheceu-se que o direito à saúde prevalece quando confrontado com os direitos de propriedade intelectual.
\end{abstract}

Entretanto, o papel da Declaração em promover o acesso a medicamentos, a partir de sua posterior emenda ao Acordo TRIPS em 2003 é questionada, pois a possibilidade da política de acesso aos medicamentos reafirmados pela Declaração de Doha acaba sendo restringida diante das assinaturas dos Tratados de Livre Comércio (TLC) (CHAVES et al., 2007). São negociações de iniciativas bilaterais, regionais e plurilaterais que ampliam as normas internacionais da OMC de regulação sobre propriedade intelectual, o que Basso (2005, p. 11) chama de novo bilateralismo da propriedade intelectual, também conhecido como TRIPS-Plus.

Vários são os tipos de dispositivos TRIPS-plus existentes nos tratados de livre comércio, dentre os quais a vigência das patentes acima de 20 anos, vínculo entre patentes e registro, restrições para o uso de licenças compulsórias, proteção dos dados para obtenção de registro sanitário, restrições para a matéria patenteável e revogação das patentes (CHAVES, 2006, p. 34).

Nota-se que existem dois importantes instrumentos, porem antagônicos. Em que

Rev. de Direito, Globalização e Responsabilidade nas Relações de Consumo | e-ISSN: 2526-0030| Goiânia| v. 5 | n. 1 | p. 43-60| Jan/Jun. 2019 
pese exista uma preocupação com as questões atinentes à saúde pública por parte dos países em desenvolvimento traduzidos na Declaração de Doha, há, concomitantemente, os Tratados de Livre Comércio (TLC) que restringem as flexibilidades e protegem ainda mais os direitos dos titulares das patentes (AIRES, 2018, p. 45). Nesse sentido, tem-se a Declaração de Doha como "importante instrumento político conquistado pelos países em desenvolvimento na IV Ministerial da OMC" e, na contramão, os Tratados de Livre Comércio (TLC) que reduz "o escopo de possibilidades de implementação das flexibilidades do Acordo TRIPS” (CHAVES et al.,2007).

Diante desse cenário, observa-se que esses obstáculos tornam o Sistema Internacional de Patentes um instrumento de proteção para o titular da patente, na medida em que reforça os direitos patentários, o que restringe, consequentemente, o acesso a medicamentos. Por isso, importa refletir sobre os instrumentos normativos que vão de encontro aos direitos previstos no âmbito nacional e internacional, como é o caso do direito à saúde, a fim de que a estrutura normativa de proteção aos direitos de propriedade intelectual concilie os direitos sobre a propriedade com os interesses sociais.

\section{CONSIDERAÇÕES FINAIS}

Diante do exposto, percebe-se que a indústria de medicamentos na sociedade globalizada atua com estratégias de poder que visam regular a vida das populações, estabelecendo parâmetros de doenças e saúde. Agem na sociedade civil através do fomento da lógica consumista, criando a cada dia novas drogas para novas doenças.

Dessa forma, a multidão, enquanto foco de controle social, adere a novas formas de controle como única maneira de participar da vida em sociedade. Os interesses econômicos das grandes corporações multinacionais durante as negociações do Acordo TRIPS, demonstrou que o Estado torna-se parceiro nas técnicas de biopoder ao lado da sociedade civil, a qual acaba aderindo-as e viabilizando, ainda que maneira indireta, o "controle" da população.

Compreende-se como controle, pois, muito embora existam opções à serem escolhidas, a sociedade representada pelos seus cidadãos estarão, tradicionalmente, condicionas a escolher as delimitações que o mercado oferece. Tal como uma falsa

Rev. de Direito, Globalização e Responsabilidade nas Relações de Consumo | e-ISSN: 2526-0030| Goiânia| v. 5 
sensação de liberdade, lubridiando quem compreende estar no controle de suas ações.

Nesse sentido, o fortalecimento dos Estados nacionais como fenômeno derivado do advento da biopolítica é apenas um dos efeitos que se pode destacar dessa transformação do poder político ocorrido na modernidade. Logo, percebe-se a difícil tarefa de efetivar o direito à saúde, uma vez que diante da relação entre homo oecnomicus, a sociedade civil "consumista" e o Estado - através de técnicas biopolíticas -, formam a governamentalidade desenvolvida por Foucault, a qual articula instrumentos de controle social.

Verifica-se, portanto, o grande desafio contemporâneo de resguardar os direitos à saúde já conquistados, e avançar socialmente, no sentido de atender demandas sociais de saúde pública, contrapondo todo controle que vise antes da garantia à saúde, o fomendo da economia e lucro, que muito embora seja importante, não deve se sobrepor as necessidas básicas de saúde.

\section{REFERÊNCIAS}

Acordo sobre aspectos dos direitos de propriedade intelectual relacionados ao comércio. Acordo TRIPS. Disponível em: <http://www.inpi.gov.br/legislacao- 1/27-tripsportugues1.pdf $>$. Acesso em: 02 jan. 2019.

AIRES, Marco Antônio Pontes. O sistema internacional de patentes e a saúde global: As implicações no controle das doenças tropicais negligenciadas no brasil. Dissertação de Mestrado. Programa de Pós- graduação em Direito da Universidade Federal de Santa Maria - RS. 2018.

ANVISA, Agência Nacional de Vigilância Sanitária. Estatístico do Mercado Financeiro de 2016. Brasília, 2017. Disponível em:

<http://portal.anvisa.gov.br/documents/374947/3413536/Anu\%C3\%A1rio+Estt\%C3\%A Dstic o+do+Mercado+Farmac\%C3\%AAutico+-+2016/485ddf50-a37f- 469f-89e529643c5c9df5>. Acesso em 05 jan. 2019.

BASSO, Maristela. O Direito Internacional da Propriedade Intelectual. Porto Alegre: Livraria do Advogado, 2005.

BOTH, Valdevir. O biopoder e o discurso dos direitos humanos: um estudo a partir de Michel Foucault. Dissertação de Mestrado em Filosofia, Universidade do Vale do Rio dos Sinos, São Leopoldo.2008. Disponível em:

<http://www.educadores.diaadia.pr.gov.br/arquivos/File/2010

/artigos_teses/FILOSOFIA/Dissertacoes/Valdevir_Both.pdf>. Acesso em: 13 jan. 2019. 
CARNEIRO, Henrique. Drogas: muito além da hipocrisia. In: Post no Blog Outras Palavras. 2011. Disponível em: <http://outraspalavras.net/posts/drogas- muito-alemdahipocrisia/>.

Acesso em: 14 jan. 2019.

CAPONI, Sandra. Classificar e medicar: a gestão biopolítica dos sofrimentos psíquicos. In: Revista Interthesis, 101- 122. 2012. Disponível em:

<https://periodicos.ufsc.br/index.php/interthesis/article/view/1 807-

1384.2012v9n2p101>. Acesso em: 13 jan. 2019.

CHANG, Ha-Joon. Chutando a escada: a estratégia do desenvolvimento em perspectiva histórica. São Paulo: Editora Unesp. 2004.

CHAVES, Gabriela Costa; OLIVEIRA, Maria Auxiliadora; HASENCLEVER, Lia; MELO, Luiz Martins de. A evolução do sistema internacional de propriedade intelectual: proteção patentária para o setor farmacêutico e acesso a medicamentos. Cadernos de Saúde Pública, vol.23 no.2 Rio de Janeiro. Fev. 2007. Disponível em: $<$ http://www.scielo.br/scielo.php?script=sci_arttext\&pid=S0102-

311X2007000200002> Acesso em: 05 de jan. 2019.

DOUGLAS, Mary; ISHERWOOD, Baron. O mundo dos bens: para uma antropologia do consumo. Rio de Janeiro: Editora UFRJ, 2004.

GIDDENS, Anthony. As Consequências da Modernidade. Tradução de Raul Fiker. São Paulo: UNESP, 1991.

FOUCAULT, Michel. A Verdade e as Formas Jurídicas. 2.ed. Rio de Janeiro: Nau Ed., 1999.

. Microfísica do Poder. 26.ed. Rio de Janeiro: Edições Graal, 1979.

Vigiar e punir. Petrópolis: Vozes, 2009.

Em defesa da sociedade. São Paulo: Martins Fontes, 2000.

Nascimento da biopolítica. São Paulo: Martins Fontes, 2008a.

FURTADO, Mariama. SZAPIRO, Ana. Promoção da Saúde e seu Alcance

Biopolítico: o discurso sanitário da sociedade contemporânea. In: Saúde Soc. São Paulo, v.21, n.4, p.811- 821, 2012. Disponível em:

<file:///C:/Users/User/Desktop/50694-Article\%20Text-62969-1-10- 20130129.pdf>. Acesso em: 09 jan. 2019.

JUNGES, Junior. Direito à saúde, Biopoder e Bioética. In: Interface - Comunicação, Saúde e Educação abr-jun 2009.

MACHADO, L. V; LESSA, P. S. (2012). Medicalização da vida: ética, saúde pública e indústria farmacêutica. In: Psicologia \& Sociedade, 3. ed. 741-743. 2012. Disponível em: < 
MCKELVEY, Maureen; ORSENIGO, Luigi. Pharmaceuticals as a sectoral innovation. System Chalmers University, University of Brescia and CESPRI, Bocconi University. Milan, november 2001.

NESPOLI, Grasiele. Biopolíticas da participação na saúde: o sus e o governo das populações. Disponível em:

<https://www.arca.fiocruz.br/bitstream/icict/13743/2/Pol\%C3\%ADticas\%20de\%2 OParticipa\%C3\%A7\%C3\%A3o\%20e\%20Sa\%C3\%BAde_Biopoliticas\%20da\%2 0Participacao\%20na\%20Saude.pdf> Acesso em: 10 jan. 2019.

ORTEGA, F. The biopolitics of health: reflections on Michel Foucault, Agnes Heller e Hannah Arendt, Interface - Comunic., Saúde, Educ., v.8, n.14, p.9-20, set.2003-

fev.2004. Disponivel em: < http://www.scielo.br/pdf/icse/v8n14/v8n14a01.pdf> Acesso em: 09 jan. 2019.

PANTOJA, Yasmin Rosa da Silva. A sociedade do (hiper)consumo e a medicalização da vida. Disponível em: <http://www.brasilcon.org.br/artigos/a- sociedade-do-hiperconsumo-e- a-medicalizacao-da-vida>. Acesso em: 06 jan. 2018.

PIMENTEL, Vitor Paiva et al. Inserção internacional das empresas farmacêuticas: motivações, experiências e propostas para o BNDES. Complexo Industrial da Saúde BNDES Setorial 40, p. 5-42, 2014. Disponível em:

<https://web.bndes.gov.br/bib/jspui/bitstream/1408/3107/2/BS\%2040\%20Inser $\% \mathrm{C} 3 \% \mathrm{~A} 7 \% \mathrm{C} 3 \% \mathrm{~A} 3 \mathrm{o} \% 20$ internacional $\% 20 \mathrm{das} \% 20 \mathrm{empresas} \% 20 \mathrm{farmac} \% \mathrm{C} 3 \%$ AAuticas_P.pdf>. Acesso em: 05 jan. 2019.

RADAELLI, Vanderléia. Trajetórias inovativas do setor farmacêutico no Brasil: tendências recentes e desafios futuros. Universidade Estadual de Campinas. Instituto de Geociências. Campinas, SP, 2012.

A nova conformação setorial da indústria farmacêutica mundial: redesenho nas pesquisas e ingresso de novos atores. $R B I$, Rio de Janeiro (RJ), 7 (2), p.445482, jul/dez 2008.

RODRIGUES, Joelson Tavares. A medicação como única resposta: uma miragem do contemporâneo. In: Psicologia em Estudo, 2003. Disponível em:

<http://www.scielo.br/pdf/pe/v8n1/v8n1a03>. Acesso em: 12 jan. 2019.

SANTOS, Boaventura de Sousa; MENESES, Maria Paula G.; NUNES, João Arriscado. Introdução: Para ampliar o cânone da ciência: a diversidade epistemológica do mundo. In: SANTOS, Boaventura de Sousa [org.] Semear outras Soluções: os caminhos da biodiversidade e dos conhecimentos rivais. Rio de Janeiro: Civilização Brasileira, 2010.

SANTIN, Janaína Rigo. As novas fontes de poder no mundo globalizado:

flexibilização ou sonegação de direitos? Disponível em: <

http://www.publicadireito.com.br/conpedi/manaus/arquivos/anais/bh/janaina_rig 
o_santin.pdf>. Acesso em: 05 jan. 2019.

TYBUSCH, Jerônimo Siqueira; TYBUSCH AGNE, Francieli. Garantias do contratualismo, meio ambiente e biopolítica: o que pode a vontade jurídica frente ao interesse econômico?. In: Luiz Ernani Bonesso de Araujo; Ãngela Araújo da Silveira Espíndola; Carlos André Hüning Birnfeld. (Org.). Direito e Sustentabilidade. 2. ed.Florianópolis: Editora FUNJAB, 2013, v. 1, p. 365-394. 